\title{
The neurotoxicity of amyloid $\beta$-protein oligomers is reversible in a primary neuron model
}

\author{
Daisuke Tanokashira' ${ }^{1}$, Naomi Mamada ${ }^{1,2}$, Fumiko Yamamoto ${ }^{1,2}$, Kaori Taniguchi ${ }^{1}$, Akira Tamaoka ${ }^{2}$, \\ Madepalli K. Lakshmana ${ }^{3}$ and Wataru Araki ${ }^{*}$ (i)
}

\begin{abstract}
Alzheimer's disease (AD) is characterized by the accumulation of extracellular amyloid $\beta$-protein $(A \beta)$ and intracellular hyperphosphorylated tau proteins. Recent evidence suggests that soluble A $\beta$ oligomers elicit neurotoxicity and synaptotoxicity, including tau abnormalities, and play an initiating role in the development of AD pathology. In this study, we focused on the unclarified issue of whether the neurotoxicity of A $\beta$ oligomers is a reversible process. Using a primary neuron culture model, we examined whether the neurotoxic effects induced by 2-day treatment with $A \beta 42$ oligomers $(A \beta-O)$ are reversible during a subsequent 2-day withdrawal period. $A \beta-O$ treatment resulted in activation of caspase- 3 and elF $2 a$, effects that were considerably attenuated following $A \beta-O$ removal. Immunocytochemical analyses revealed that $A \beta-O$ induced aberrant phosphorylation and caspasemediated cleavage of tau, both of which were mostly reversed by $A \beta-O$ removal. Furthermore, $A \beta-O$ caused intraneuronal dislocation of $\beta$-catenin protein and a reduction in its levels, and these alterations were partially reversed upon A $\mathrm{A}-\mathrm{O}$ withdrawal. The dislocation of $\beta$-catenin appeared to reflect synaptic disorganization. These findings indicate that removal of extracellular $A \beta-O$ can fully or partially reverse $A \beta-O$-induced neurotoxic alterations in our neuron model. Accordingly, we propose that the induction of neurotoxicity by $A \beta$ oligomers is a reversible process, which has important implications for the development of AD therapies.
\end{abstract}

Keywords: Alzheimer's disease, Amyloid $\beta$-protein, Neurotoxicity, Oligomer, Primary neuron, Tau, $\beta$-catenin

\section{Introduction}

Alzheimer's disease (AD) is a progressive neurodegenerative disorder characterized clinically by memory loss and cognitive decline. Its major pathological hallmarks are extracellular senile plaques and intracellular neurofibrillary tangles, which are composed of amyloid $\beta$-protein $(\mathrm{A} \beta)$ and phosphorylated tau (p-tau) protein, respectively [1]. A central role of $A \beta$ in the molecular pathology of $\mathrm{AD}$ has been established [2]. $\mathrm{A} \beta$ is generated by sequential cleavages of amyloid precursor protein (APP) by $\beta$-site APP cleaving enzyme 1 (BACE1) and $\gamma$-secretase [3]. Under pathological conditions, $A \beta$ self-aggregates to form $A \beta$ oligomers, which likely

\footnotetext{
* Correspondence: araki@ncnp.go.jp

${ }^{1}$ Department of Demyelinating Disease and Aging, National Institute of Neuroscience, National Center of Neurology and Psychiatry (NCNP), Kodaira, Tokyo 187-8502, Japan

Full list of author information is available at the end of the article
}

induce abnormalities of tau and cause cellular stress responses, including caspase activation and disturbances of synaptic structure and plasticity. Thus, $A \beta$ oligomers are considered to be an initiator of AD pathology [4-7]. The mechanisms by which $A \beta$ oligomers induce neurotoxicity, critical issues from a therapeutic standpoint, remain to be elucidated, although several hypotheses have been suggested [4-10]. The major theory is that extracellular $\mathrm{A} \beta$ oligomers interact with certain cell surface receptors to cause aberrant signal transduction. Alternatively, it has been suggested that extracellular $A \beta$ oligomers disrupt the cell membrane directly or intracellular $\mathrm{A} \beta$ oligomers elicit neurotoxicity. Although a link between $\mathrm{A} \beta$ oligomers and tau has been established $[11,12]$, signaling pathways linking the two remain elusive. It also remains to be clarified whether the neurotoxicity of $A \beta$ oligomers is reversible and abates upon their removal. 
We previously established a primary neuron culture model in which $A \beta$ oligomers trigger apparent neurotoxicity with relatively modest neuronal death [13]. In the current study, we took advantage of this system to investigate the reversibility of $\mathrm{A} \beta$ oligomers-associated neurotoxicity, characterized by caspase activation and tau abnormalities. Here, we present evidence that the neurotoxicity of $A \beta$ oligomers is reversible in primary neurons.

\section{Results}

Reversal of $A \beta$ oligomer-induced caspase- 3 and elF $2 a$ activation upon oligomer removal

We established a primary neuron culture model in which treatment of neurons at 9 days in vitro (DIV9) with $2.5 \mu \mathrm{M} A \beta 42$ oligomers $(\mathrm{A} \beta-\mathrm{O})$ exert neurotoxic effects with modest cell death [13]. In this model, $A \beta-O$ induces activation of caspase-3, a major apoptosis marker, and eIF $2 \alpha$, a mediator of various stress responses [14]. During 3 days of $\mathrm{A} \beta-\mathrm{O}$ treatment, a timedependent increase in cleaved caspase-3 levels was observed, which corresponded to a time-dependent slight decrease in cell survival [13], suggesting progression of neuronal degeneration during the treatment period. We inferred that the capacity of neurons to recover from the $\mathrm{A} \beta$-O-induced neuronal damage may be dependent on the time period of $\mathrm{A} \beta-\mathrm{O}$ exposure. In our pilot experiments, neurons appeared to recover from caspase- 3 activation and abnormal tau phosphorylation, the latter of which is described in the following section, upon withdrawal of $A \beta$ from medium on day 2, whereas they did not appear to recover considerably upon $A \beta$ removal on day 3. Therefore, we decided to investigate whether $A \beta-$ $\mathrm{O}$ neurotoxicity is reversible using the experimental protocol depicted in Fig. 1a. Neurons were incubated with or without $A \beta-O$ for 2 days, at which point cells were deprived of $\mathrm{A} \beta-\mathrm{O}$ by replacing the medium with fresh medium lacking $A \beta-O$, or were re-provided $A \beta-O$, and cultured for an additional 2 days. We first estimated the effects of $A \beta-O$ on cell survival using a Cell Counting Kit-8. A $\beta-\mathrm{O}$ treatment for 2 and 4 days decreased neuronal viability by 12 and $30 \%$, respectively, compared with controls. Neuronal viability in the treatment group in which $\mathrm{A} \beta-\mathrm{O}$ was removed after 2 days was $\sim 85 \%$ of that in controls on day 4 , a value significantly higher than that of neurons treated continuously with $\mathrm{A} \beta-\mathrm{O}$ for 4 days (Fig. 1b).

We next investigated whether cellular stress responses to $A \beta-O$ are reversible. Treatment of neurons with $A \beta-$ $\mathrm{O}$ induced a time-dependent increase in cleaved caspase-3 levels on days 2 and 4 compared with controls (Fig. 1c, d). Cleaved caspase-3 levels on day 4 in neurons deprived of $\mathrm{A} \beta-\mathrm{O}$ were significantly lower than those in neurons treated continuously with $\mathrm{A} \beta-\mathrm{O}$ for 4 days, and were even lower than those on day 2 (Fig. 1c, d).
Treatment of neurons with $\mathrm{A} \beta-\mathrm{O}$ also significantly increased the ratio of phosphorylated to total eIF2 $\alpha$ (peIF $2 \alpha /$ total eIF $2 \alpha$ ) compared with control neurons on days 2 and 4 (Fig. 1e, f). As was the case for cleaved caspase- 3 levels, the p-eIF $2 \alpha /$ total eIF $2 \alpha$ ratio in neurons deprived of $\mathrm{A} \beta-\mathrm{O}$ was significantly decreased on day 4 compared with that in neurons treated continuously with $\mathrm{A} \beta-\mathrm{O}$ for 4 days, and appeared lower than that on day 2 (Fig. 1e, f). These data indicate that removal of extracellular $\mathrm{A} \beta-\mathrm{O}$ reverses $\mathrm{A} \beta-\mathrm{O}$-induced activation of caspase- 3 and eIF $2 \alpha$.

\section{Aberrant tau phosphorylation induced by $A \beta-O$ treatment is reversed upon oligomer removal}

Recent evidence suggests a link between $\mathrm{A} \beta-\mathrm{O}$ and tau abnormalities $[11,12]$. To analyze this linkage, we examined abnormal tau phosphorylation by immunocytochemistry using antibodies specific for p-tau (AT8 and PHF-1) or unphosphorylated tau (Tau-1). Total tau immunoreactivity was localized mostly in neurites (likely axons) of neurons (Fig. 2a), and was slightly decreased after 2 or 4 days of continuous exposure; this small decrease was largely eliminated in neurons deprived of $\mathrm{A} \beta$ $\mathrm{O}$ (Fig. 2e). p-Tau was similarly located in neurites of neurons (Fig. 2b, c). Continuous $\mathrm{A} \beta-\mathrm{O}$ treatment significantly increased p-tau levels in neurons, measured as the intensity of AT8 or PHF-1 signals normalized to that of total tau, on days 2 and 4 compared with that in control neurons (Fig. $2 \mathrm{a}-\mathrm{c}, \mathrm{e}-\mathrm{g}$ ). In contrast, the intensity of unphosphorylated Tau-1 immunoreactivity in neurons continuously treated with $\mathrm{A} \beta-\mathrm{O}$ was significantly reduced compared with that in control neurons on days 2 and 4 (Fig. 2d, h). Notably, in neurons deprived of $A \beta$ $\mathrm{O}$, both the intensity of $\mathrm{p}$-tau immunoreactivity, revealed by AT 8 and PHF-1 signals, and the intensity of unphosphorylated Tau-1 immunoreactivity, were restored to levels similar to those in control neurons on day 4 (Fig. 2b-d, f-h).

A further analysis of tau phosphorylation by Western blot analysis showed that relative levels of unphosphorylated tau (Tau-1) to total tau in $\mathrm{A} \beta-\mathrm{O}$-treated neurons decreased on days 2 and 4 compared with controls, and tended to recover upon $\mathrm{A} \beta-\mathrm{O}$ withdrawal on day 4 (Additional file 1: Figure S1). Although AT8 and PHF1 unexpectedly failed to yield consistent results in Western blotting, our findings collectively suggest that $\mathrm{A} \beta-\mathrm{O}$ induced abnormalities of tau phosphorylation are reversible upon oligomer removal.

\section{$A \beta-O-i n d u c e d$ caspase cleavage of tau is reversed upon oligomer removal}

It is known that activated caspase mediates the truncating cleavage of tau $[15,16]$. To investigate whether $A \beta-O$ affects tau cleavage, we performed immunocytochemistry 
a

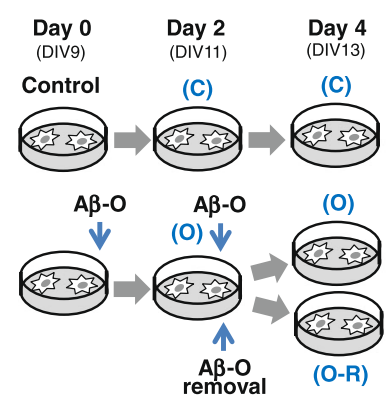

C

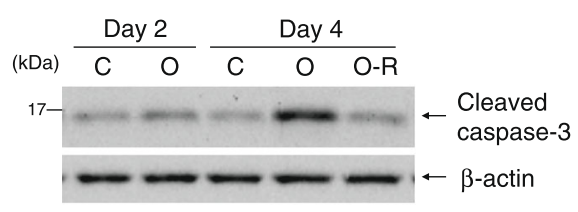

e

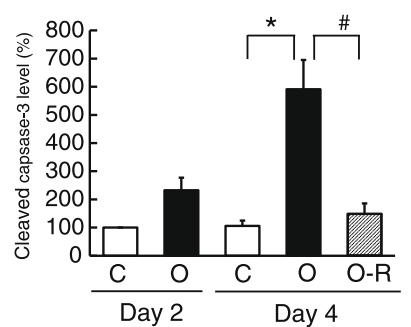

b

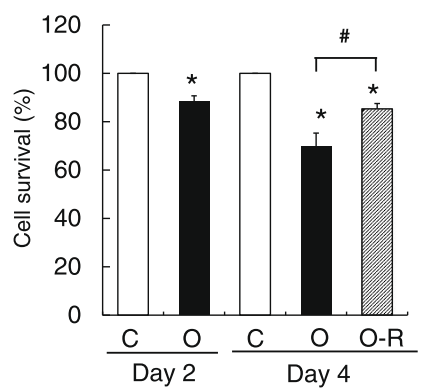

d

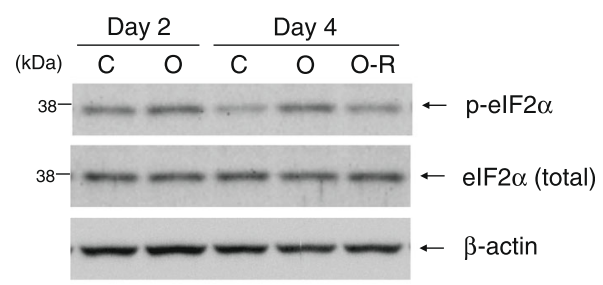

f

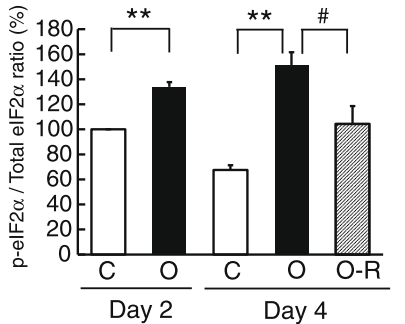

Fig. 1 Effects of A $\beta-O$ treatment and removal on caspase-3 and elF2a in primary cortical neurons. a Experimental design. Primary neurons (DIV9) were treated with $2.5 \mu \mathrm{M} A \beta-\mathrm{O}(\mathrm{O})$ or vehicle $(\mathrm{C})$ for 2 days. On day 2, A $\mathrm{B}-\mathrm{O}$-treated neurons were washed and further treated with $\mathrm{A} \beta-\mathrm{O}(\mathrm{O})$ or deprived of $A \beta-O(O-R)$ for an additional 2 days. Control neurons $(C)$ were similarly cultured for an additional 2 days. b Cell survival assay. Cell survival was analyzed by CCK-8 assay as described in Methods. The graph shows survival levels relative to those in controls on day 2 or 4 . c Cells were lysed on day 2 or 4, and cell lysates were analyzed by Western blotting using an anti-cleaved caspase-3 antibody. $\mathbf{d}$ Cleaved caspase-3 levels were quantified and expressed relative to those in control neurons on day 2. e Cell lysates were analyzed by Western blotting using anti-elF2a or anti-p-elF2 $a$ antibodies. $\mathbf{f}$ Total and p-elF2a levels were quantified and expressed as $p$-elF2a/total elF2a ratios relative to those in control neurons on day 2. Data represent means \pm SEM from three separate experiments. ${ }^{*} p<0.05,{ }^{* *} p<0.01$, compared with control. \#p $<0.05$, compared with Aß-O-treated cells

using an antibody specific for the caspase-cleaved form of tau. A limited number of untreated neurons were immunopositive for cleaved tau, but on days 2 and 4 following treatment with $\mathrm{A} \beta-\mathrm{O}$, the percentage of cleaved-taupositive cells was notably increased compared with control neurons (Fig. 3a, b). Removal of $A \beta-O$ substantially reduced the proportion of cells positive for cleaved tau, restoring it to a value similar to that in controls on day 4 (Fig. 3a, b).

$A \beta-O$ treatment causes abnormal alterations in $\beta$-catenin that are partially reversible upon oligomer removal

It has been reported that $A D$ pathology is associated with disrupted Wnt/ $\beta$-catenin signaling $[17,18]$. $\beta$ catenin also plays important roles in the regulation of synaptic structures and plasticity $[19,20]$. To investigate the involvement of $\beta$-catenin in the neurotoxic mechanism of $\mathrm{A} \beta-\mathrm{O}$, we first analyzed the intraneuronal localization of $\beta$-catenin by immunocytochemistry. $\beta$ catenin immunoreactivity was mainly observed in punctate structures over neurites of control neurons, suggesting synaptic localization, consistent with the role of $\beta$-catenin in synaptic vesicle localization and presynaptic assembly [19]. Continuous $A \beta-O$ treatment decreased the intensity of $\beta$-catenin immunoreactivity in neurons on days 2 and 4 compared with that in controls (Fig. 4a, b). Interestingly, $\mathrm{A} \beta-\mathrm{O}$ apparently induced a dramatic change in the intraneuronal localization of $\beta$ catenin; positive immunoreactivities were observed mainly in neurites and neuronal soma with markedly reduced punctate staining, implying a shift from synapses to neurites and soma. Withdrawal of $\mathrm{A} \beta-\mathrm{O}$ partially reversed the 


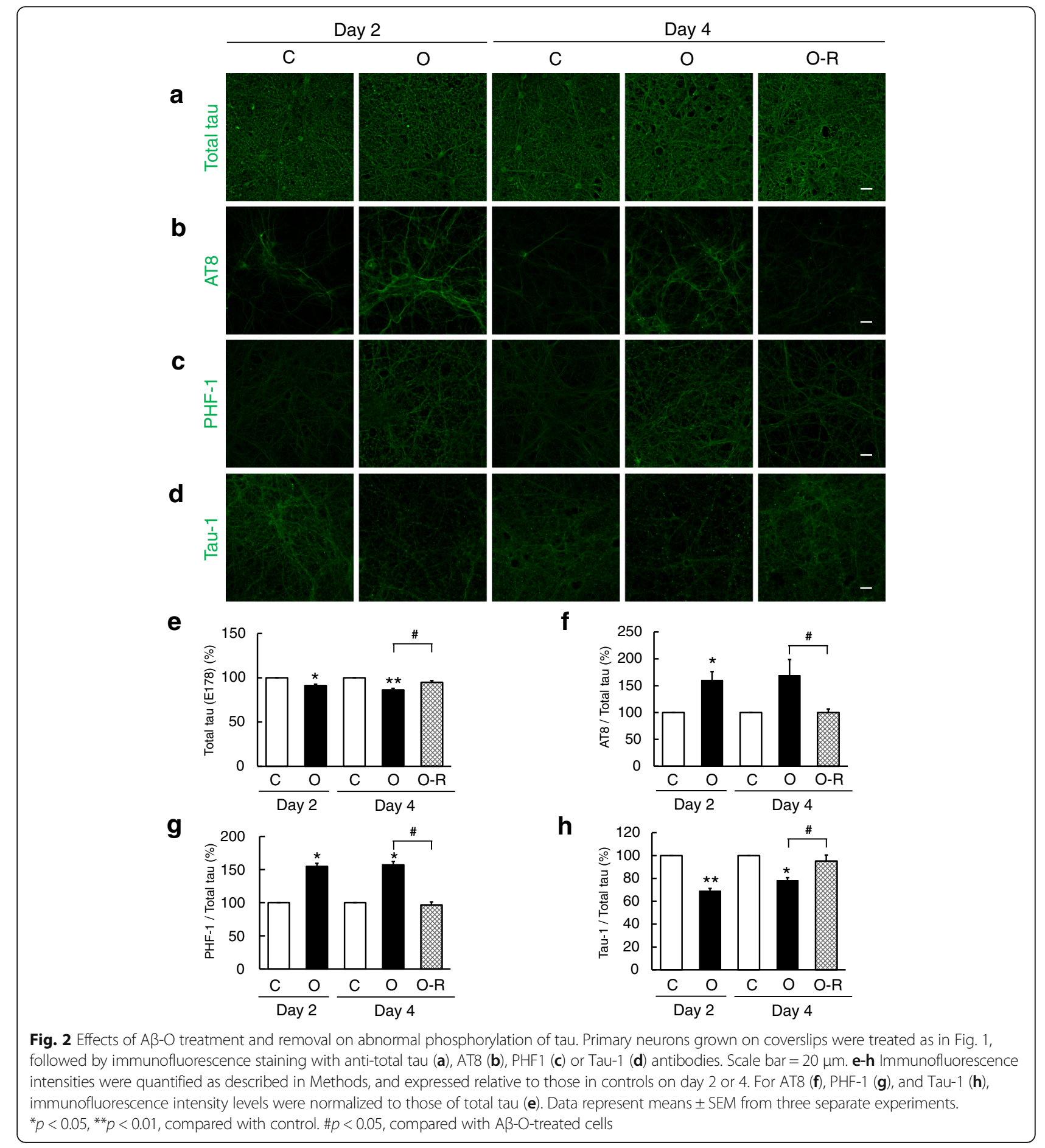

decreased intensity of $\beta$-catenin immunoreactivity as well as its abnormal intraneuronal localization on day 4 compared with neurons treated continuously with $A \beta-O$ (Fig. 4a, b). We further analyzed the protein level of $\beta$ catenin by Western blotting. $\beta$-catenin levels in control neurons increased with the age of the culture and were lower in $\mathrm{A} \beta$-O-treated neurons than control neurons on days 2 and 4 (Fig. 4c, d). Upon A $\beta-O$ withdrawal, $\beta$ - catenin recovered to a level intermediate between those in control and $\mathrm{A} \beta$-O-treated cells (Fig. 4c, d). In addition, continuous $A \beta-O$ treatment induced a significant, timedependent reduction in the phospho- $\beta$-catenin ( $\mathrm{p}-\beta$-catenin)/total $\beta$-catenin ratio compared with controls on days 2 and 4 that was partially reversed on day 4 by removal of $\mathrm{A} \beta-\mathrm{O}$ (Fig. 4c, e). To examine the relationship between $A \beta-O$-induced $\beta$-catenin alterations and synapses, 


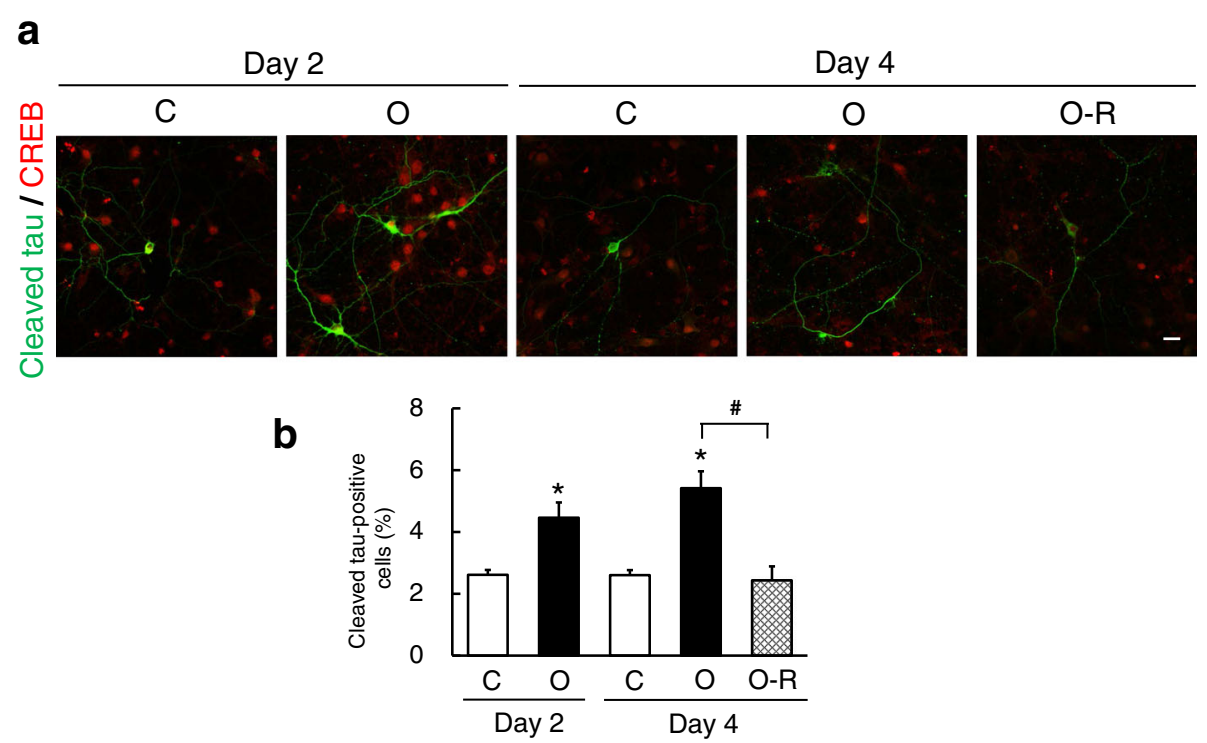

Fig. 3 Effects of A $\mathrm{A}-\mathrm{O}$ treatment and removal on aberrant cleavage of tau. a Primary neurons grown on coverslips were treated as in Fig. 1, followed by double-immunofluorescence staining with anti-cleaved tau (green) and anti-CREB (red) antibodies. Scale bar $=20$ um. b The percentage of all CREB-positive cells positive for cleaved tau was calculated as described in Methods and graphed. Data represent means \pm SEM from three separate experiments. ${ }^{*} p<0.05$, compared with control. $\# p<0.05$, compared with A $\mathrm{A}$-O-treated cells

we performed double immunostaining of $\beta$-catenin and SNAP-25, a presynaptic SNARE protein [21]. We observed that both proteins underwent similar alterations in intraneuronal localization following $\mathrm{A} \beta-\mathrm{O}$ treatment (Additional File 2: Figure. S2), implying that the abnormal alterations of $\beta$-catenin are associated with disorganization of synapses.

\section{Discussion}

We have established a primary neuronal culture model in which relatively low concentrations of $A \beta-O$ induce modest neuronal death. Our data showed that $A \beta-O$ induces activation of caspase- 3 and eIF $2 \alpha$, and abnormal phosphorylation and cleavage of tau. These abnormal alternations have been reported to be present in $\mathrm{AD}$ brains [11, 12, 14, 15, 22-24], suggesting that our model reflects the characteristic features of AD pathology. Our study also provides evidence of a direct link between $\mathrm{A} \beta-\mathrm{O}$ and tau abnormalities, in accord with previous studies [25-30]. To evaluate whether $A \beta-O$ neurotoxicity is a reversible or irreversible process, we used an experimental paradigm in which neurons exposed to $\mathrm{A} \beta-\mathrm{O}$ for 2 days were further treated with $\mathrm{A} \beta-\mathrm{O}$ for 2 additional days or were deprived of $A \beta-O$ for this same culture period. We then compared control and $\mathrm{A} \beta-\mathrm{O}-$ treated neurons on day 2 , and control, $\mathrm{A} \beta-\mathrm{O}$-treated and $\mathrm{A} \beta-\mathrm{O}-$ deprived neurons on day 4 . We first focused on caspase-3 and eIF $2 \alpha$, both of which are thought to be important in mediating AD neurodegenerative processes $[15,24]$. We found that the levels of cleaved caspase- 3 and p-eIF $2 \alpha$ in A $\beta$-O-deprived neurons were much lower on day 4 than those in neurons continuously treated with $\mathrm{A} \beta-\mathrm{O}$, and were similar to those in controls. These findings suggest that neurons can recover following $\mathrm{A} \beta-\mathrm{O}$ removal, even after neuronal injury responses to $\mathrm{A} \beta-\mathrm{O}$ have already progressed.

We examined the abnormal phosphorylation of tau by detection with the antibodies AT8 and PHF-1, which recognize major phosphorylation sites characteristic of AD [31]. Immunocytochemically, AT8 and PHF-1 signals increased whereas unphosphorylated Tau-1 immunoreactivity decreased on days 2 and 4 in neurons treated continuously with $\mathrm{A} \beta-\mathrm{O}$ compared with those in control neurons. Intriguingly, $\mathrm{A} \beta-\mathrm{O}$ removal reversed these alterations in AT8, PHF-1, and Tau-1 immunoreactivities. In considering possible mechanisms underlying this recovery, we note that the phosphorylation sites recognized by AT 8 and PHF-1 are known to be targeted by the major tau kinases GSK3 $\beta$ and Cdk5 $[32,33]$; thus, A $\beta$ O-induced abnormal tau phosphorylation may be attributable to activation of these kinases [31]. Accordingly, it is possible that $\mathrm{A} \beta-\mathrm{O}$ removal may induce deactivation of these kinases, leading to dephosphorylation of tau at the corresponding target sites. In addition, it is conceivable that the activity of tau-targeted phosphatases also increases following A $\beta-\mathrm{O}$ withdrawal.

Our analyses further demonstrated that $\mathrm{A} \beta-\mathrm{O}$ treatment increased the proportion of neurons positive for cleaved tau on days 2 and 4, and showed that this effect was fully reversed following $\mathrm{A} \beta-\mathrm{O}$ deprivation for 2 days. It is likely that $A \beta-O$ induces tau cleavage through 
a

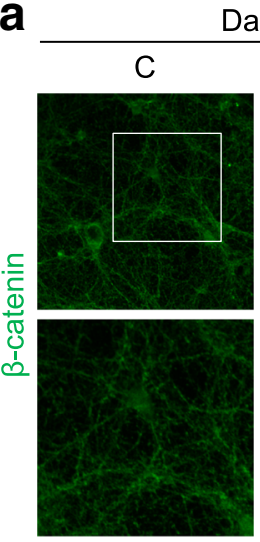

Day 2

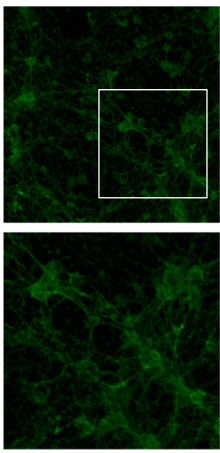

b

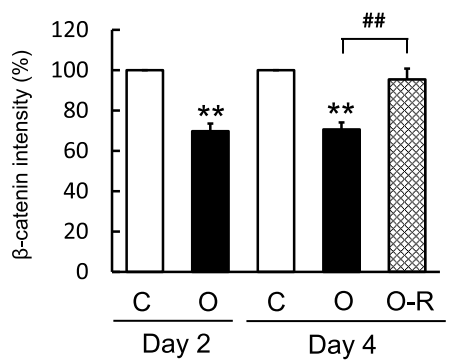

d

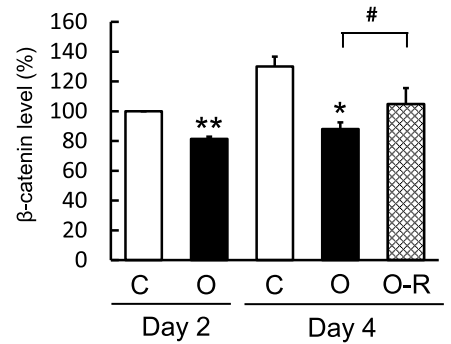

0

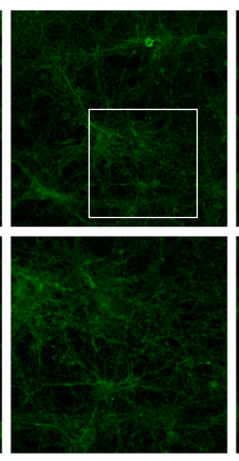

O-R

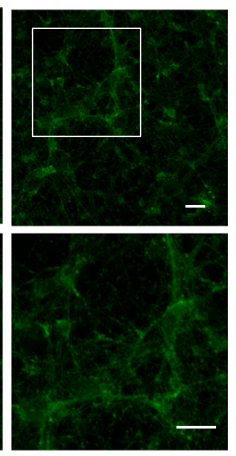

C

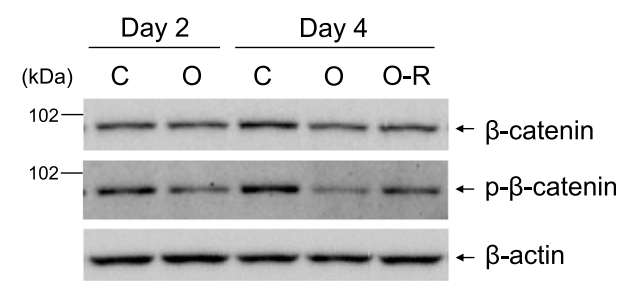

e

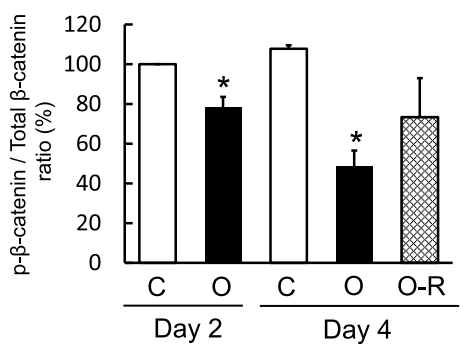

Fig. 4 Effects of $A \beta-O$ treatment and removal on $\beta$-catenin in primary cortical neurons. a Primary neurons grown on coverslips were treated as in Fig. 1, followed by immunofluorescence staining with an anti- $\beta$-catenin antibody. Bottom panel shows high-magnification images of the regions depicted by white squares in upper images. Scale bar $=20 \mu \mathrm{m}$. b Immunofluorescence intensity of $\beta$-catenin staining was quantified as described in Methods and expressed relative to levels in control neurons on day 2 or 4 . Data represent means \pm SEM from three separate experiments. c Primary neurons were treated as in Fig. 1, followed by Western blot analysis of cell lysates using the indicated antibodies. $\mathbf{d}$, e $\beta$-catenin (d) levels and p- $\beta$-catenin/total $\beta$-catenin ratios $(\mathbf{e})$ expressed relative to those in control neurons on day 2 . Data represent means \pm SEM from three separate experiments. ${ }^{*} p<0.05$,

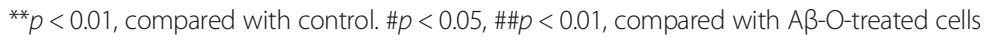

caspase activation, since caspase-3 is known to cleave tau at Asp421 [15]. Consistent with this view, the reversal of tau cleavage paralleled with that of caspase- 3 activation upon $\mathrm{A} \beta-\mathrm{O}$ withdrawal. Recent studies have suggested that cleaved tau is prone to aggregate and may act as a seed for formation of aggregates [22], and that caspase-mediated cleavage of tau initiates tangle formation [34]. Moreover, cleaved tau appears to be preferentially released from neurons for possible interneuronal transmission $[35,36]$. Taken together, our findings that abnormal phosphorylation and truncation of tau induced by $\mathrm{A} \beta-\mathrm{O}$ were reversed upon oligomer removal suggest that these tau alternations are reversible processes. It has been suggested that $A \beta$ oligomers induce tau missorting from axons to dendrites [37, 38]. Further studies are necessary to investigate whether such tau missorting occurs in our model system.

We found that the localization pattern of $\beta$-catenin was markedly altered by $\mathrm{A} \beta-\mathrm{O}$ treatment, implying dissociation of $\beta$-catenin from synapses. Further, $\beta$-catenin levels were decreased in A $\beta-O-$ treated neurons compared with controls. We observed that $A \beta-O$ removal reversed these abnormal $\beta$-catenin alterations, consistent with the idea that $\mathrm{A} \beta-\mathrm{O}-$-induced neuronal insults are 
reversible. $A \beta$-O-induced $\beta$-catenin dislocation may be associated with perturbation of synaptic organization. This possibility is supported by our observation that SNAP-25 was similarly dislocated upon $A \beta-O$ treatment (Fig. S2). Consistent with this, synapsin I, a representative presynaptic protein, and $\alpha \mathrm{N}$-catenin, a binding partner of $\beta$-catenin [39], were observed to exhibit similar abnormal dislocation following $\mathrm{A} \beta-\mathrm{O}$ treatment (data not shown). These observations are consistent with the notion that $\mathrm{A} \beta$ oligomers disrupt synaptic structures and functions in vitro and in vivo $[4,6,7,40]$.

Many reports have suggested that disturbances in $\mathrm{Wnt} / \beta$-catenin signaling are linked to $\mathrm{AD}[17,18]$. $\mathrm{A} \beta$ induced activation of apoptosis and synaptotoxicity are reported to be antagonized by certain Wnt agonists such as Wnt-3a, implying that $A \beta$ disrupts Wnt signaling, possibly through interaction with frizzled receptors [41-45]. Since the Wnt signaling pathway negatively regulates GSK3 $\beta$ [46], it is plausible that treatment with $A \beta$ oligomers inhibits Wnt/ $\beta$-catenin signaling and induces activation of GSK3 $\beta$. In the canonical Wnt signaling pathway, phosphorylation of $\beta$-catenin by GSK3 $\beta$ facilitates $\beta$-catenin degradation $[17,18]$. However, our finding that $p$ - $\beta$-catenin levels were reduced by $A \beta-O$ exposure suggests that the decrease in $\beta$-catenin in our experimental system was independent of $\beta$-catenin phosphorylation.
Several hypotheses have been suggested to account for the mechanism by which $A \beta$ oligomers induce neurotoxicity [4-10]. One major model is that extracellular $A \beta$ oligomers interact with certain cell surface receptors, resulting in aberrant signal transduction $[4-7,10]$. Alternatively, it has been suggested that $A \beta$ oligomers disrupt the cell membrane directly or that intracellular $A \beta$ oligomers cause neurotoxicity $[8,9]$. Our demonstration that pathological alternations induced by $A \beta-O$ can be reversed by its extracellular removal tends to favor the idea that $A \beta-O$ neurotoxicity is mediated by certain cell-surface proteins; thus, at least under our experimental conditions, other models appear unlikely (Fig. 5).

Our results indicate that neurotoxicity induced by $A \beta$ oligomers is a reversible process in that neurons are capable of recovering from the moderate neurotoxic insults. The present findings are consistent with a small number of prior reports. Lee et al. [47] showed that the impairment in synaptic activity induced by short-term treatment with $A \beta$ oligomers is reversible. Brikha et al. [48] used mouse organotypic slices to show that $A \beta$-induced spine loss recovers following $A \beta$ washout. An in vivo study using APP transgenic mice reported that A $\beta$ associated neuritic dystrophy can be recovered by application of anti-A $\beta$ antibody [49]. More importantly, a recent study reported that cognitive dysfunction in APP

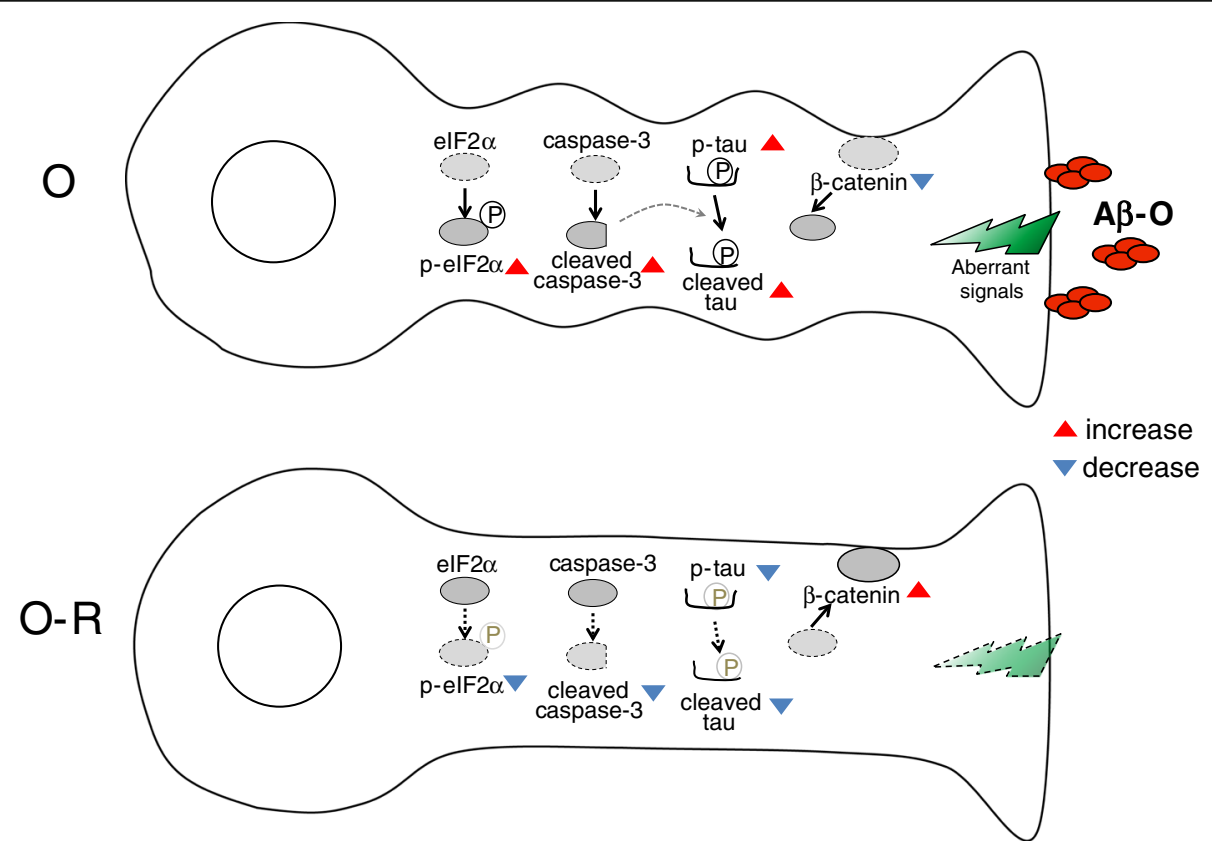

Fig. 5 Schema illustrating a possible mechanism by which neurotoxic effects of AB-O are reversed by its removal. A -O possibly acts on the cell surface of neurons to transmit aberrant signals, resulting in various abnormal cellular responses, including caspase-3 activation, elF2a activation, tau phosphorylation and cleavage, and abnormal subcellular localization of $\beta$-catenin and a reduction in its levels (upper schema, O). Caspase activation is likely responsible for tau cleavage. The alterations of $\beta$-catenin may be associated with disorganization of synapses. Upon A $\beta-O$ removal, the aberrant signals subside, resulting in reversal of all abnormal responses (lower schema, O-R) 
transgenic mice is restored following suppression of the transgene, an effect that was attributed to a reduction in $A \beta$ oligomers [50]. This in vivo observation appears to be consistent with our in vitro findings, and suggests that any treatment designed to remove or reduce $A \beta$ oligomers would be effective against AD. One example of such treatments is immunotherapy targeting $A \beta$ oligomers, which has been shown to reduce $A \beta$ burden and improve synaptic and cognitive deficits in animal models [51, 52]. Clinical trials of passive immunotherapy using antibodies specific for $A \beta$ oligomers are in progress [53]. In addition, the use of BACE1 inhibitors to prevent $A \beta$ oligomer accumulation is also a promising therapeutic option [54].

In summary, we investigated the reversibility of $A \beta$ oligomer-induced neurotoxicity, using a neuron model system which reflects the characteristic features of $A D$ pathology. We demonstrated that $\mathrm{A} \beta-\mathrm{O}$ treatment induces activation of caspase- 3 and eIF $2 \alpha$, aberrant phosphorylation and caspase-mediated cleavage of tau, and abnormal alterations in $\beta$-catenin, and showed that all of these abnormalities were fully or partially reversed upon extracellular removal of $\mathrm{A} \beta-\mathrm{O}$. These findings collectively suggest that $A \beta$ oligomers-associated neurotoxicity is a reversible process, supporting the view that treatments targeting $A \beta$ oligomers have significant therapeutic potential for AD. Further studies on the molecular mechanisms underlying the reversibility of $A \beta$ oligomers-induced neurotoxicity will contribute to the development of novel therapeutic strategies to treat or prevent AD.

\section{Methods}

\section{Cell culture}

Primary neuronal cultures were prepared from cerebral cortices of rat embryos at embryonic day 17, essentially as described previously $[13,55]$. Neurons were plated on poly-L-lysine-coated plates or dishes at a density of 680 cells $/ \mathrm{mm}^{2}$. Cells were maintained in a humidified atmosphere of $5 \% \mathrm{CO}_{2} / 95 \%$ air in Macs Neuro Medium (Miltenyi Biotec, Auburn, CA, USA) containing $0.5 \mathrm{mM}$ L-glutamine, NeuroBrew-21 (Miltenyi Biotec), and penicillin-streptomycin. Half of the medium was replaced with fresh medium every 3-4 days.

\section{$A \beta$ preparation and treatment}

A $\beta 42$ oligomers $(A \beta-O)$ were prepared as described previously $[13,56]$. Briefly, human $A \beta(1-42)$ peptide (Peptide Institute, Osaka, Japan) was dissolved in 1,1,1,3,3,3hexafluoro-2-propanol (HFIP; Sigma, St Louis, MO, USA) in a chemical fume hood to obtain a $1 \mathrm{mM}$ solution. HFIP was evaporated overnight in the hood and further under vacuum for $1 \mathrm{~h}$, and dried peptide films were stored at $-30{ }^{\circ} \mathrm{C}$. Prior to use, a $5 \mathrm{mM}$ stock was prepared by dissolving dried $\mathrm{A} \beta$ peptide in dimethyl sulfoxide (DMSO), and sonicating it in an ultrasonic bath sonicator for $10 \mathrm{~min}$. Oligomers were prepared by diluting $5 \mathrm{mM}$ A $\beta$ DMSO stock to $0.1 \mathrm{mM}$ with DMEM/F12 without phenol red and left for 1 day at $4{ }^{\circ} \mathrm{C}$. Immediately before addition to DIV9 neurons, $\mathrm{A} \beta-\mathrm{O}$ preparations were diluted to $2.5 \mu \mathrm{M}$ with neuronal medium and used to replace the entire medium. Control cultures were treated with the same concentration of DMSO [13]. After A $\beta-O$ treatment for 2 days, the cells were rinsed twice and incubated with fresh medium with or without $\mathrm{A} \beta-\mathrm{O}$ for an additional 2 days (Fig. 1a).

\section{Antibodies}

The antibodies used were as follows: anti-cleaved caspase3 (Asp175) (Cell Signaling, Danvers, MA, USA); anti-eIF2 $\alpha$ (Assay Biotechnology, Sunnyvale, CA, USA); anti-p-eIF2 $\alpha$ (Ser51) (Cell Signaling); AT8, which recognizes tau protein phosphorylated at Ser202 and Thr205 (Thermo Scientific, Rockford, IL, USA); PHF-1, which recognizes tau phosphorylated at Ser396 and Ser404 [57] (provided by Dr. Peter Davies); Tau-1, which recognizes unphosphorylated epitopes between residues 192 and 204 (Millipore, Darmstadt, Germany); anti-cleaved tau (Asp421) (Millipore); anti-total tau (E178, Abcam, Cambridge, MA, USA; Tau-5, Thermo Scientific); anti-CREB (Gene Tex, Irvine, CA, USA); anti- $\beta$-catenin (Cell Signaling); anti-p- $\beta$-catenin (Ser33 + Ser37) (Abcam); anti-SNAP-25 (BioLegend, San Diego, CA, USA) and anti- $\beta$-actin (Wako, Osaka, Japan).

\section{Western blot analysis}

Cells were lysed in radioimmunoprecipitation assay (RIPA) buffer containing protease inhibitors and phosphatase inhibitors, and cell lysates were prepared as described previously [13]. For Western analysis of tau, cells were lysed in sodium dodecyl sulfate (SDS) lysis buffer (62.5 mM Tris pH 6.8, 2\% SDS, 10\% glycerol, $1 \mathrm{mM}$ dithiothreitol, $5 \mathrm{mM}$ EDTA) containing protease inhibitors and phosphatase inhibitor cocktail, and heated at $95{ }^{\circ} \mathrm{C}$ for $10 \mathrm{~min}$, followed by centrifugation at 100,000 $\mathrm{g}$ for $30 \mathrm{~min}$. Western blotting of cell lysates was performed using a standard procedure, as described previously [13]. Protein band densities were quantified using an LAS1000 image analyzer (Fuji Film Co., Tokyo, Japan).

\section{Cell survival assay}

Cell survival assays were performed as described previously [13]. Briefly, primary cortical neurons cultured on 12 -well plates were treated with $\mathrm{A} \beta-\mathrm{O}$ or vehicle, as described above. Cell Counting Kit-8 solution (Dojindo, Kumamoto, Japan) was added to each well, and the plates were left in a $\mathrm{CO}_{2}$ incubator for $2 \mathrm{~h}$. Absorbance was measured at $450 \mathrm{~nm}$ using a microplate reader. Absorbance of the medium, used as a blank, was subtracted from that of each sample. 


\section{Immunocytochemistry}

Immunocytochemical analyses were performed as described previously $[13,58]$. Briefly, primary neurons cultured on coverslips were fixed with $4 \%$ paraformaldehyde in phosphate-buffered saline (PBS). Fixed cells were permeabilized and blocked with $0.3 \%$ Triton X-100 and $1 \%$ horse serum in PBS, and incubated with primary antibody for $1 \mathrm{~h}$, followed by incubation with Alexa488conjugated anti-mouse or anti-rabbit IgG secondary antibodies (Molecular Probes, Eugene, OR, USA) for $1 \mathrm{~h}$. For double-immunofluorescence staining, cells were subsequently incubated with another primary antibody and Alexa568-conjugated specific secondary antibody. Specimens were observed under an LSM 780 laserscanning confocal microscope (Carl Zeiss, Jena, Germany). Images illustrating antibody labeling were acquired using a $20 \times 0.8$ N.A. dry objective. The mean fluorescence intensity of tau (E178), AT8, PHF-1 and Tau-1 was quantified using the entire image $(212.55 \times$ $212.55 \mu \mathrm{m})$ as the region of interest. In every immunostaining experiment, 4-5 images were analyzed for each condition. The values for AT8, PHF-1 and Tau-1 were normalized to that of tau (E178). Cleaved tau was analyzed in cells doubly immunostained with antibodies against cleaved tau and CREB, the latter of which was used to visualize viable neurons. The percentage of CREB-positive neurons positive for cleaved tau in the whole image was calculated. Five images were analyzed for each condition in every experiment.

\section{Statistical analysis}

All results are presented as means \pm SEMs. Data were statistically analyzed using one-way analysis of variance (ANOVA) followed by a Tukey multiple comparison test or Student's $t$-test with a significance threshold of $p<0.05$.

\section{Additional files}

Additional file 1: Figure S1. Western blot analysis of tau phosphorylation. Primary neurons treated as in Fig. 1 were lysed in SDS lysis buffer. Cell lysates were analyzed by Western blotting using antitotal tau (Tau-5) and Tau- 1 antibodies. Tau-1/Tau-5 ratios were expressed relative to those in control neurons on day 2 or 4 . Data represent means \pm SEM from three separate experiments. ${ }^{*} p<0.05$, compared with control. $\# p<0.05$, compared with A $\beta-O-$-treated cells. (PDF $1333 \mathrm{~kb}$ )

Additional file 2: Figure S2. The relationship between $A \beta-O-i n d u c e d$ alterations of $\beta$-catenin and synapses. Primary neurons treated as in Fig. were doubly immunostained with anti- $\beta$-catenin (green) and anti-SNAP25 (red). Similar alterations in intraneuronal localization of both proteins were observed following $A \beta-O$ treatment and removal. Evident colocalization was not observable between the two proteins. (PDF $548 \mathrm{~kb}$ )

\section{Abbreviations}

$A D$ : Alzheimer's disease; $A \beta$ : Amyloid $\beta$-protein; $A \beta-O$ : $A \beta 42$ oligomers;

DIV: Days in vitro; PBS: Phosphate-buffered saline; $\mathrm{p}$-tau: Phosphorylated tau.

\section{Acknowledgments}

The authors thank Dr. Peter Davies for providing PHF1 antibody, and Dr. Yumiko M. Araki for suggestions.

\section{Funding}

This work was supported, in part, by a Grant-In-Aid for Scientific Research (22590951, 16 K09688, 16 K09664) from JSPS, Japan, an Intramural Research Grant (27-9, 28-9) for Neurological and Psychiatric Disorders of the National Center of Neurology and Psychiatry, and an International grant from the Alzheimer's and Aging Research Center, Torrey Pines Institute for Molecular Studies, U.S.A.

\section{Availability of data and materials}

All data generated or analyzed during this study are included in this published article and its Additional files 1 and 2 .

\section{Authors' contributions}

WA conceived and designed the study. AT and MKL assisted in designing the study. WA, DT, NM, FY, and KT performed the experiments and analyzed the data. WA and DT wrote the manuscript, and MKL proofread it. All authors read and approved the final manuscript.

\section{Competing interests}

The authors declare that they have no competing interest.

\section{Consent for publication}

Not applicable.

\section{Ethics approval and consent to participate}

The animal procedures involved in this study were reviewed and approved by the Institutional Animal Investigation Committee at the National Institute of Neuroscience, NCNP.

\section{Author details}

${ }^{1}$ Department of Demyelinating Disease and Aging, National Institute of Neuroscience, National Center of Neurology and Psychiatry (NCNP), Kodaira, Tokyo 187-8502, Japan. ${ }^{2}$ Department of Neurology, Faculty of Medicine University of Tsukuba, Tsukuba, Ibaraki 305-8575, Japan. ${ }^{3}$ Torrey Pines Institute for Molecular Studies, Port St. Lucie 34987-2352, Florida, USA

Received: 14 October 2016 Accepted: 28 December 2016

Published online: 31 January 2017

\section{References}

1. Duyckaerts C, Delatour B, Potier MC. Classification and basic pathology of Alzheimer disease. Acta Neuropathol. 2009;118:5-36.

2. Hardy J, Selkoe DJ. The amyloid hypothesis of Alzheimer's disease: progress and problems on the road to therapeutics. Science. 2002;297:353-56.

3. De Strooper B, Vassar R, Golde T. The secretases: enzymes with therapeutic potential in Alzheimer disease. Nat Rev Neurol. 2010;6:99-107.

4. Koffie RM, Hyman BT, Spires-Jones TL. Alzheimer's disease: synapses gone cold. Mol Neurodegener. 2011;6:63.

5. Hefti F, Goure WF, Jerecic J, Iverson KS, Walicke PA, Krafft GA. The case for soluble $A B$ oligomers as a drug target in Alzheimer's disease. Trends Pharmacol Sci. 2013;34:261-66.

6. Tu S, Okamoto S, Lipton SA, Xu H. Oligomeric Aß-induced synaptic dysfunction in Alzheimer's disease. Mol Neurodegener. 2014;9:48.

7. Viola KL, Klein WL. Amyloid $\beta$ oligomers in Alzheimer's disease pathogenesis, treatment, and diagnosis. Acta Neuropathol. 2015;129: 183-206.

8. Kagan BL, Hirakura Y, Azimov R, Azimova R, Lin MC. The channel hypothesis of Alzheimer's disease: current status. Peptides. 2002:23:1311-15.

9. LaFerla FM, Green KN, Oddo S. Intracellular amyloid-beta in Alzheimer's disease. Nat Rev Neurosci. 2007:8:499-509.

10. Xia M, Cheng X, Yi R, Gao D, Xiong J. The binding receptors of $A \beta$ : an alternative therapeutic target for Alzheimer's disease. Mol Neurobiol. 2016; 53:455-71.

11. Stancu IC, Vasconcelos B, Terwel D, Dewachter I. Models of $\beta$-amyloid induced Tau-pathology: the long and "folded" road to understand the mechanism. Mol Neurodegener. 2014;9:51. 
12. Lloret A, Fuchsberger T, Giraldo E, Viña J. Molecular mechanisms linking amyloid $\beta$ toxicity and Tau hyperphosphorylation in Alzheimer's disease. Free Radic Biol Med. 2015;83:186-91.

13. Mamada N, Tanokashira D, Hosaka A, Kametani F, Tamaoka A, Araki W. Amyloid $\beta$-protein oligomers upregulate the $\beta$-secretase, BACE1, through a post-translational mechanism involving its altered subcellular distribution in neurons. Mol Brain. 2015;8:73

14. Harding HP, Zhang Y, Zeng H, Novoa I, Lu PD, Calfon M, et al. An integrated stress response regulates amino acid metabolism and resistance to oxidative stress. Mol Cell. 2003;11:619-33.

15. Rissman RA, Poon WW, Blurton-Jones M, Oddo S, Torp R, Vitek MP, et al. Caspase-cleavage of tau is an early event in Alzheimer disease tangle pathology. J Clin Invest. 2004;114:121-30.

16. Rohn TT. The role of caspases in Alzheimer's disease; potential novel therapeutic opportunities. Apoptosis. 2010;15:1403-09.

17. Oliva CA, Vargas JY, Inestrosa NC. Whts in adult brain: from synaptic plasticity to cognitive deficiencies. Front Cell Neurosci. 2013;7:224

18. Purro SA, Galli S, Salinas PC. Dysfunction of Wnt signaling and synaptic disassembly in neurodegenerative diseases. J Mol Cell Biol. 2014;6:75-80.

19. Bamji SX, Shimazu K, Kimes N, Huelsken J, Birchmeier W, Lu B, et al. Role of beta-catenin in synaptic vesicle localization and presynaptic assembly. Neuron. 2003;40:719-31.

20. Maguschak KA, Ressler KJ. The dynamic role of beta-catenin in synaptic plasticity. Neuropharmacology. 2012;62:78-88.

21. Südhof TC, Rizo J. Synaptic vesicle exocytosis. Cold Spring Harb Perspect Biol. 2011;3:a005637.

22. Binder LI, Guillozet-Bongaarts AL, Garcia-Sierra F, Berry RW. Tau, tangles, and Alzheimer's disease. Biochim Biophys Acta. 2005;1739:216-23.

23. Snigdha S, Smith ED, Prieto GA, Cotman CW. Caspase-3 activation as a bifurcation point between plasticity and cell death. Neurosci Bull. 2012;28:14-24.

24. Lourenco MV, Ferreira ST, De Felice FG. Neuronal stress signaling and elF2a phosphorylation as molecular links between Alzheimer's disease and diabetes. Prog Neurobiol. 2015;129:37-57.

25. De Felice FG, Wu D, Lambert MP, Fernandez SJ, Velasco PT, Lacor PN, et al. Alzheimer's disease-type neuronal tau Hyperphosphorylation induced by a beta oligomers. Neurobiol Aging. 2008;29:1334-47.

26. Jin M, Shepardson N, Yang T, Chen G, Walsh D, Selkoe DJ. Soluble amyloid $\beta$-protein dimers isolated from Alzheimer cortex directly induce Tau hyperphosphorylation and neuritic degeneration. Proc Natl Acad Sci U S A. 2011;108:5819-24

27. Zhang Z, Zhao R, Qi J, Wen S, Tang Y, Wang D. Inhibition of glycogen synthase kinase- $3 \beta$ by Angelica sinensis extract decreases $\beta$-amyloidinduced neurotoxicity and tau phosphorylation in cultured cortical neurons. J Neurosci Res. 2011:89:437-47.

28. Park H, Kam TI, Kim Y, Choi H, Gwon Y, Kim C, et al. Neuropathogenic role of adenylate kinase-1 in A $\beta$-mediated tau phosphorylation via AMPK and GSK3ß. Hum Mol Genet. 2012;21:2725-37.

29. Killick R, Ribe EM, Al-Shawi R, Malik B, Hooper C, Fernandes C, et al. Clusterin regulates $\beta$-amyloid toxicity via Dickkopf-1-driven induction of the wnt-PCPJNK pathway. Mol Psychiatry. 2014;19:88-98.

30. Deng $Y$, Xiong Z, Chen $P$, Wei J, Chen S, Yan Z. $\beta$-amyloid impairs the regulation of $\mathrm{N}$-methyl-D-aspartate receptors by glycogen synthase kinase 3. Neurobiol Aging. 2014;35:449-59.

31. Iqbal K, Gong CX, Liu F. Microtubule-associated protein tau as a therapeutic target in Alzheimer's disease. Expert Opin Ther Targets. 2014;18:307-18.

32. Dolan PJ, Johnson GV. The role of tau kinases in Alzheimer's disease. Curr Opin Drug Discov Devel. 2010;13:595-603.

33. Kimura T, Ishiguro K, Hisanaga S. Physiological and pathological phosphorylation of tau by Cdk. Front Mol Neurosci. 2014;7:65.

34. de Calignon A, Fox LM, Pitstick R, Carlson GA, Bacskai BJ, Spires-Jones TL, et al. Caspase activation precedes and leads to tangles. Nature. 2010;464:1201-04.

35. Kanmert D, Cantlon A, Muratore CR, Jin M, O'Malley TT, Lee G, et al. Cterminally truncated forms of Tau, but Not full-length Tau or its C-terminal fragments, Are released from neurons independently of cell death. J Neurosci. 2014;35:10851-65.

36. Sokolow S, Henkins KM, Bilousova T, Gonzalez B, Vinters HV, Miller CA, et al. Pre-synaptic C-terminal truncated tau is released from cortical synapses in Alzheimer's disease. J Neurochem. 2015;133:368-79.
37. Zempel $H$, Thies E, Mandelkow E, Mandelkow EM. Abeta oligomers cause localized $\mathrm{Ca}(2+)$ elevation, missorting of endogenous Tau into dendrites, Tau phosphorylation, and destruction of microtubules and spines. J Neurosci. 2010;30:11938-50.

38. Noble W, Hanger DP, Miller CC, Lovestone S. The importance of tau phosphorylation for neurodegenerative diseases. Front Neurol. 2013:4:83.

39. Maiden SL, Hardin J. The secret life of a-catenin: moonlighting in morphogenesis. J Cell Biol. 2011;195:543-52.

40. Cochran JN, Hall AM, Roberson ED. The dendritic hypothesis for Alzheimer's disease pathophysiology. Brain Res Bull. 2014;103:18-28.

41. De Ferrari GV, Chacón MA, Barría MI, Garrido JL, Godoy JA, Olivares G, et al. Activation of Wnt signaling rescues neurodegeneration and behavioral impairments induced by beta-amyloid fibrils. Mol Psychiatry. 2003;8:195-208

42. Alvarez AR, Godoy JA, Mullendorff K, Olivares GH, Bronfman M, Inestrosa NC. Wnt-3a overcomes beta-amyloid toxicity in rat hippocampal neurons. Exp Cell Res. 2004;297:186-96.

43. Farías GG, Godoy JA, Vázquez MC, Adani R, Meshulam H, Avila J, et al. The anti-inflammatory and cholinesterase inhibitor bifunctional compound IBUPO protects from beta-amyloid neurotoxicity by acting on Wnt signaling components. Neurobiol Dis. 2005;18:176-83.

44. Chacón MA, Varela-Nallar L, Inestrosa. Frizzled-1 is involved in the neuroprotective effect of Wnt3a against Abeta oligomers. J Cell Physiol. 2008;217:215-27.

45. Vargas JY, Ahumada J, Arrázola MS, Fuenzalida M, Inestrosa NC. WASP-1, a canonical Wnt signaling potentiator, rescues hippocampal synaptic impairments induced by A $\beta$ oligomers. Exp Neurol. 2015;264:14-25.

46. Chen RH, Ding WV, McCormick F. Wnt signaling to $\beta$-catenin involves two interactive components: glycogen synthase kinase-3ßinhibition and activation of protein kinase C. J Biol Chem. 2000;275:17894-99.

47. Lee S, Zemianek J, Shea TB. Rapid, reversible impairment of synaptic signaling in cultured cortical neurons by exogenously-applied amyloid- $\beta$. J Alzheimers Dis. 2013:35:395-402.

48. Shrestha BR, Vitolo OV, Joshi P, Lordkipanidze T, Shelanski M, Dunaevsky A. Amyloid beta peptide adversely affects spine number and motility in hippocampal neurons. Mol Cell Neurosci. 2006;33:274-82.

49. Brendza RP, Bacskai BJ, Cirrito JR, Simmons KA, Skoch JM, Klunk WE, et al. Anti-Abeta antibody treatment promotes the rapid recovery of amyloidassociated neuritic dystrophy in PDAPP transgenic mice. J Clin Invest. 2005; 115:428-33.

50. Fowler SW, Chiang AC, Savjani RR, Larson ME, Sherman MA, Schuler DR, et al. Genetic modulation of soluble $A \beta$ rescues cognitive and synaptic impairment in a mouse model of Alzheimer's disease. J Neurosci. 2014;34: 7871-85.

51. Lord A, Gumucio A, Englund H, Sehlin D, Sundquist VS, Söderberg L, et al. An amyloid-beta protofibril-selective antibody prevents amyloid formation in a mouse model of Alzheimer's disease. Neurobiol Dis. 2009;36:425-34.

52. Wisniewski T, Goñi F. Immunotherapeutic approaches for Alzheimer's disease. Neuron. 2015:85:1162-76.

53. Lannfelt L, Möller C, Basun H, Osswald G, Sehlin D, Satlin A, et al. Perspectives on future Alzheimer therapies: amyloid- $\beta$ protofibrils - a new target for immunotherapy with BAN2401 in Alzheimer's disease. Alzheimers Res Ther. 2014;6:16.

54. Yan $R$, Vassar R. Targeting the $\beta$ secretase BACE1 for Alzheimer's disease therapy. Lancet Neurol. 2014;13:319-29.

55. Brewer GJ, Torricelli JR, Evege EK, Price PJ. Optimized survival of hippocampal neurons in B27-supplemented Neurobasal, a new serum-free medium combination. J Neurosci Res. 1993;35:567-76.

56. Stine WB, Jungbauer $L, Y u C$, LaDu MJ. Preparing synthetic $A \beta$ in different aggregation states. Methods Mol Biol. 2011;670:13-32.

57. Otvos Jr L, Feiner L, Lang E, Szendrei Gl, Goedert M, Lee VM. Monoclonal antibody PHF-1 recognizes tau protein phosphorylated at serine residues 396 and 404. J Neurosci Res. 1994;39:669-73.

58. Tanokashira D, Motoki K, Minegishi S, Hosaka A, Mamada N, Tamaoka A, et al. LRP1 downregulates the Alzheimer's $\beta$-secretase BACE1 by modulating its intraneuronal trafficking. Eneuro. 2015;2:0006-15. 